02

\title{
Создание и исследование органических светоизлучающих структур, содержащих массивы коллоидных квантовых точек*
}

\author{
() М. А. Еремеев, И.И. Михайлов, М.Д. Павлова, И.А. Ламкин, С.А. Тарасов \\ Санкт-Петербургский государственный электротехнический университет „ЛЭТИ“ имени В.И. Ульянова (Ленина), \\ 197022 Санкт-Петербург, Россия \\ e-mail: markeremeev22@gmail.com
}

Поступила в редакцию 11.01.2018 г.

Созданы органические электролюминесцентные структуры ITO/TPD/Alq3/A1 и ITO/PEDOT:PSS/TPD/ Alq3/Al, представляющие собой органические светоизлучающие диоды (OLED). Проведены эксперименты по внедрению коллоидных квантовых точек $\mathrm{CdSe} / \mathrm{ZnS}$ в активный слой структуры. Использованы методы оптической спектроскопии для оценки параметров создаваемых структур. Продемонстрирована целесообразность использования метода быстрого вакуумного термического осаждения в качестве основного метода нанесения слоев структуры и показана возможность ускоренного формирования слоев материала без нарушения его химической структуры. С помощью измерения спектров фотолюминесценции в разных точках образцов произведен контроль качества получаемых структур, составлены карты распределения мощности излучения и толщины материала. Сформулированы рекомендации к созданию верхних контактов и других областей светоизлучающих структур. Созданы органические структуры с коллоидными квантовыми точками ITO/PEDOT:PSS/TPD/TPD + CQD's CdSe/Alq3/Al, в которых достигнута электролюминесценция квантовых точек $\mathrm{CdSe} / \mathrm{ZnS}$ для широкого диапазона подаваемых напряжений. Показано, что введение коллоидных квантовых точек в структуру приводит к значительной модификации спектра электролюминесценции.

DOI: $10.21883 /$ OS.2018.05.45948.8-18

\section{Введение}

Создание и исследование коллоидных квантовых точек (ККТ) и приборов на их основе являются одними из самых перспективных направлений в современной электронике [1-5]. Вместе с тем в последние годы все большую актуальность приобретают органические полупроводниковые материалы и приборы на их основе, в частности, органические светоизлучающие диоды (OLED). Это вызвано тем, что их использование позволяет создавать экраны с низким энергопотреблением, высокой скоростью работы и улучшенной цветопередачей. Типичная структура OLED состоит из прозрачной подложки, прозрачного анода, транспортных слоев с дырочной и электронной проводимостью, активного слоя, а также катода. В последние годы начались исследования структур органических светодиодов, содержащих в составе активного слоя ККТ [6]. Квантовые точки, внедренные в структуру OLED, позволяют повысить эффективность прибора благодаря высокому квантовому выходу люминесценции и дают возможность управлять свойствами излучения [7].

В ходе работы были созданы органические электролюминесцентные структуры, содержащие в своем составе КKT CdSe, излучающие на длине волны $650 \mathrm{~nm}$. В процессе создания структур отдельные слои и готовые структуры исследовались с использованием методик оптической спектроскопии (ОС) и сканирующей электронной спектроскопии. Проведенные исследования

\footnotetext{
* Х Международная конференция молодых ученых и специалистов „Оптика 2017“, 16-20 октября 2017 г., Санкт-Петербург, Россия
}

были необходимы для определения оптических свойств создаваемых слоев и структур, контроля их качества и однородности, а также оценки целесообразности использования вакуумного термического осаждения в качестве основного метода, используемого для создания слоев структуры. На первом этапе были проведены измерения спектров фотолюминесценции (ФЛ) и поглощения ККТ и отдельных слоев маломолекулярных соединений, которые в дальнейшем использовались как компоненты электролюминесцентных структур. В ходе нанесения слоев на поверхность подложки могут изменяться характеристики наносимых материалов. Исследования методами ОС проводились на каждом этапе формирования органических светоизлучающих структур. Было произведено сравнение спектров ФЛ материалов до и после нанесения на подложку, что позволило продвинуться в определении наилучших технологических параметров создания структур. В результате работы были созданы органические светоизлучающие структуры, содержащие массивы ККТ, в которых возникала электролюминесценция (ЭЛ) в результате комбинации рекомбинационных переходов в квантовых точках и органических слоях. Были изучены спектры ЭЛ и вольт-амперные характеристики структуры, а также произведен их анализ в сравнении со спектрами ФЛ материалов-компонентов структур.

\section{Эксперимент}

В работе были использованы ККТ CdSe, покрытые широкозонной оболочкой $\mathrm{ZnS}$ [8], с лигандами олеил- 


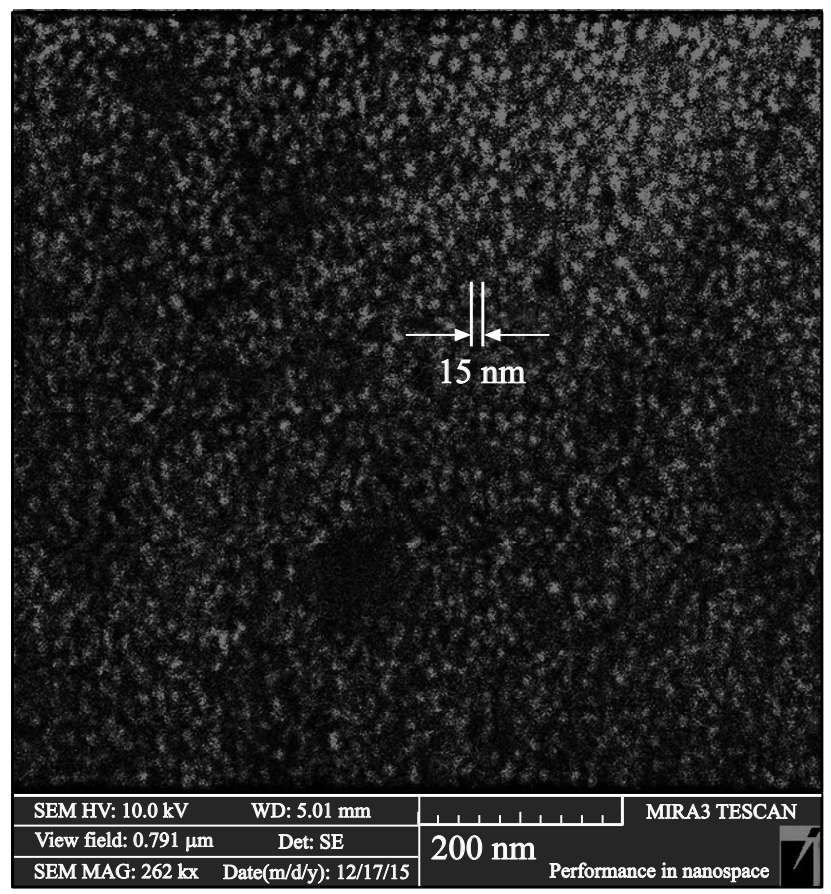

Рис. 1. Коллоидные квантовые точки $\mathrm{CdSe} / \mathrm{ZnS}$, осажденные на подложку. Изображение получено с использованием метода сканирующей электронной спектроскопии.

амин/триоктилфосфин. Наночастицы хранились в виде коллоидного раствора в толуоле, концентрация $0.1 \mathrm{~g} / \mathrm{ml}$. В качестве основного материала для исследований были выбраны ККТ, максимум пика ФЛ которых находится на длине волны $645 \mathrm{~nm}$, поскольку такие точки обладали наибольшим квантовым выходом люминесценции (более 80\%). Средний размер ККТ составлял $15 \mathrm{~nm}$ с учетом наличия оболочек.

Изначально были исследованы спектры поглощения и ФЛ использованных наночастиц. На спектре поглощения в области $600 \mathrm{~nm}$ наблюдался экстремум, обусловленный экситонным поглощением в ККТ. Этот экситонный максимум несколько уширен вследствие дисперсии частиц по размерам. В то же время эта дисперсия была не столь велика, о чем свидетельствует небольшое значение ширины спектра ФЛ на полувысоте (около $25 \mathrm{~nm}$ ). Для изучения влияния на свойства ККТ процедуры осаждения на твердую подложку были проведены исследования с использованием методик сканирующей электронной микроскопии (рис. 1). Видно, что дисперсия по размерам для осажденных частиц оставалась в пределах 1-2 nm.

Для создания транспортных слоев структуры были использованы следующие материалы - PEDOT:PSS, TPD и Alq3. Материал PEDOT:PSS (Poly(3,4-ethylenedioxythiophene) polystyrene sulfonate) представляет собой полимерную смесь двух иономеров. Один компонент в этой смеси состоит из полистиролсульфоната натрия, другими словами, сульфированного полистирола. Часть сульфонильных групп депротонирована и несет отрицательный заряд. Другой компонент, поли (3,4-этилендиокситиофен), или PEDOT является проводящим полимером и основан на политиофене. Этот материал использовался для облегчения транспорта положительных зарядов через структуру. Значения энергий уровней нижней незаполненной молекулярной орбитали (LUMO) и верхней заполненной молекулярной орбитали (НОMO), соответствующих краям разрешенных зон в неорганических полупроводниковых материалах, составляют 3.4 и $5 \mathrm{eV}$ соответственно. Материал TPD (N,N'-Bis(3-methylphenyl)-N,N'-diphenylbenzidine) - органическое низкомолекулярное соединение, обладающее улучшенной дырочной проводимостью. Орбитали LUMO и HOMO этого материала соответствуют значениям 2.2 и $5.4 \mathrm{eV}$ соответственно. Материал Alq3 (Tris-(8-hydroxyquinoline)aluminum) - органическое низкомолекулярное соединение, одновременно выполняющее функции электроннотранспортного, активного и дырочно-блокирующего слоев. Значения энергетических уровней LUMO и HOMO составляют 3.1 и $5.7 \mathrm{eV}$ соответственно.

Соединение PEDOT:PSS хорошо растворимо в воде и других растворителях, потому оно наносилось на положку методом центрифугирования. Исследования показали, что для увеличения адгезии к подложке материал PEDOT:PSS следует растворять в изопропиловом спирте в соотношении $1: 5$.

Материалы TPD и Alq3 наносились методом быстрого вакуумного термического осаждения с помощью вакуумного поста ВУП-4. Такой метод нанесения маломолекулярных соединений не является типичным при создании OLED. Чаще используется метод медленного термического осаждения в инертной среде, скорость роста слоев при котором составляет единицы нанометров в минуту, что позволяет точнее контролировать толщину слоев. В то же время известно [9], что повышение скорости роста слоев приводит к образованию более однородной поверхности слоя и благотворно сказывается на характеристиках структуры. Возникло предположение, что для органических структур, в особенности содержащих массивы ККТ, обеспечение наилучшей однородности материала может оказаться более важным фактором, чем прецизионный контроль толщины слоев. Проведенные исследования показали высокую применимость методики быстрого вакуумного распыления для формирования органических светоизлучающих структур, что позволило создать образцы с ЭЛ распределенных массивов ККТ.

Была отработана методика создания слоев низкомолекулярных соединений методом термического осаждения в вакууме при давлении остаточных газов не выше $2 \cdot 10^{-5} \mathrm{~mm} \mathrm{Hg}$. Скорость нанесения слоя составляла $10 \mathrm{~nm} / \mathrm{s}$ и более. Осаждение производилось из керамического тигля, подогреваемого молибденовым нагревателем. Для оценки применимости данного метода были проведены предварительные исследования отдельных слоев TPD и Alq3, нанесенных на стеклянные подложки. Опасностью, возникающей при повышении скорости 
распыления, является возможность разрушения структуры органических соединений при их излишнем нагреве. Проведенные эксперименты позволили добиться сохранения высокого качества материала при существенном увеличении скорости нанесения и повышении однородности. Это, в частности, подтверждается спектрами ФЛ и поглощения созданных слоев. Данные спектры демонстрировали, что положения максимумов пиков спектров ФЛ соединений TPD и Alq3 соответствуют длинам волн 395 и $525 \mathrm{~nm}$ соответственно. Полученные спектры практически идентичны классическим спектрам этих материалов, представленным в литературе [10,11]. Полуширины спектров ФЛ соединений TPD и Alq3 были весьма невелики - 100 и $50 \mathrm{~nm}$ соответственно, что также говорит о высоком качестве полученного материала. При этом материал не подвергался продолжительному воздействию повышенных температур, что является недостатком метода медленного распыления.

Следующим этапом было создание органических светоизлучающих структур ITO/TPD/Alq3/Al и ITO/PEDOT:PSS/TPD/Alq3/Al, не содержащих ККT в составе активного слоя. Это позволило отработать технологию создания органических светоизлучающих диодов [7]. В качестве подложки использовались стекло или кварцевое стекло, с нанесенным полупрозрачным электродом на основе оксида индия олова (ITO). Для части структур также в качестве электрода использовался оксид олова, легированный фтором (FTO). Слои TPD и Alq3 создавались методом быстрого вакуумного термического осаждения без развакууммирования рабочей камеры при создании интерфейса. Слой TPD играл роль дырочно-транспортного слоя. Слой Alq3 одновременно выполнял функции активного слоя и электроннотранспортного слоя. Были исследованы спектры ЭЛ структуры и ФЛ материала Alq3. Было видно, что спектр ЭЛ сдвигается в коротковолновую область на $5 \mathrm{~nm}$ по сравнению со спектром ФЛ. Это явление можно объяснить проникновением части носителей в TPD с дальнейшей рекомбинацией в нем. Однако было выяснено, что этот эффект не столь значителен, что говорит о достаточных блокирующих свойствах слоя TPD. Добавление в структуру слоя PEDOT:PSS позволило добиться снижения барьера в нижней части структуры, что облегчило транспорт носителей заряда и дало возможность понизить рабочие напряжения излучателя.

На основе результатов предыдущих этапов работы была создана органическая электролюминесцентная структура ITO/PEDOT:PSS/TPD/TPD + CQD's CdSe/Alq3/Al. В качестве матрицы для массива ККТ $\mathrm{CdSe} / \mathrm{ZnS}$ был использован слой TPD, который наносился методом центрифугирования из смеси TPD и ККТ, растворенных в толуоле. Для оценки качества получаемых слоев были сняты спектры ФЛ и ЭЛ образцов. Регистрация спектров ФЛ производились на трех следующих этапах:

- создание структуры ITO/PEDOT:PSS/TPD,

- создание структуры ITO/PEDOT:PSS/TPD/TPD + + CQD's CdSe,
- создание структуры ITO/PEDOT:PSS/TPD/TPD + + CQD's CdSe/Alq3.

При исследовании оптических и электрических свойств образцов использовалась установка на основе зондовой станции и спектрометра быстрого сканирования OceanOptics USB4000. Для регистрации спектров с повышенным разрешением применялся спектрометр OceanOptics HR4000. Зондовая станция подключалась к подсистеме электрических измерений, позволяющей исследовать вольт-амперные, спектральные и ваттамперные характеристики при изменении напряжений в диапазоне $10^{-4}-100 \mathrm{~V}$ и токов в диапазоне $10^{-8}-1 \mathrm{~A}$. При исследовании оптических и электрических свойств образцов было использовано разработанное программное обеспечение на основе среды LabView, которое позволяло наблюдать и регистрировать изменение оптических спектров в режиме реального времени с шагом от $3 \mathrm{~ms}$ с одновременным измерением электрических характеристик. Для регистрации спектров пропускания и ФЛ также использовалась оптическая система на основе двухрешеточного монохроматора СДЛ-1, обеспечивающая разрешение до $0.01 \mathrm{~nm}$.

На рис. 2, $a$ представлен итоговый спектр ФЛ структуры ITO/PEDOT:PSS/TPD/TPD + CQD's CdSe/Alq3, полученный на третьем этапе измерений. Пик с максимумом излучения на $410 \mathrm{~nm}$ соответствует ФЛ TPD, пик с максимумом на $540 \mathrm{~nm}$ - слоя Alq3, а пик с максимумом на $645 \mathrm{~nm}$ соответствует излучению массива ККТ. Для определения однородности создаваемых слоев в структуре исследования ФЛ проводились поточечно с использованием сканирования возбуждающего лазерного пучка по поверхности образца с шагом $3 \mathrm{~mm}$ (рис. 2, б). Из спектров ФЛ была найдена мощность оптического излучения, измеренная в условных единицах. Далее для каждого этапа была составлена карта отклонения мощности излучения ФЛ от среднего значения.

Из рис. 2 видно, что для средней части образцов достигнут достаточный уровень однородности излучения и, как следствие, распределения массы материала. Увеличение отклонения на внешних границах образца объясняется технологическими особенностями процесса центрифугирования и некоторым увеличением количества материала на краях образца вследствие сильного поверхностного натяжения. При формировании последующих слоев этот эффект усугубляется. В настоящее время ведутся работы по снижению этого эффекта. Таким образом, для создания качественной структуры следует избегать нанесения верхних алюминиевых контактов в областях, примыкающих к краям подложки. Тем не менее, слои на большей части образца были весьма однородны по толщине и составу, что позволило при отступе в $4 \mathrm{~mm}$ от края образца создать матрицу светодиодных чипов с высокой однородностью мощности излучения.

В завершающей части работы были созданы электролюминесцентные структуры ITO/PEDOT:PSS/ TPD/TPD + CQD's CdSe/Alq3/Al и ITO/PEDOT:PSS/ TPD/Alq3/Al (рис. 3). Видно, что введение ККТ в 

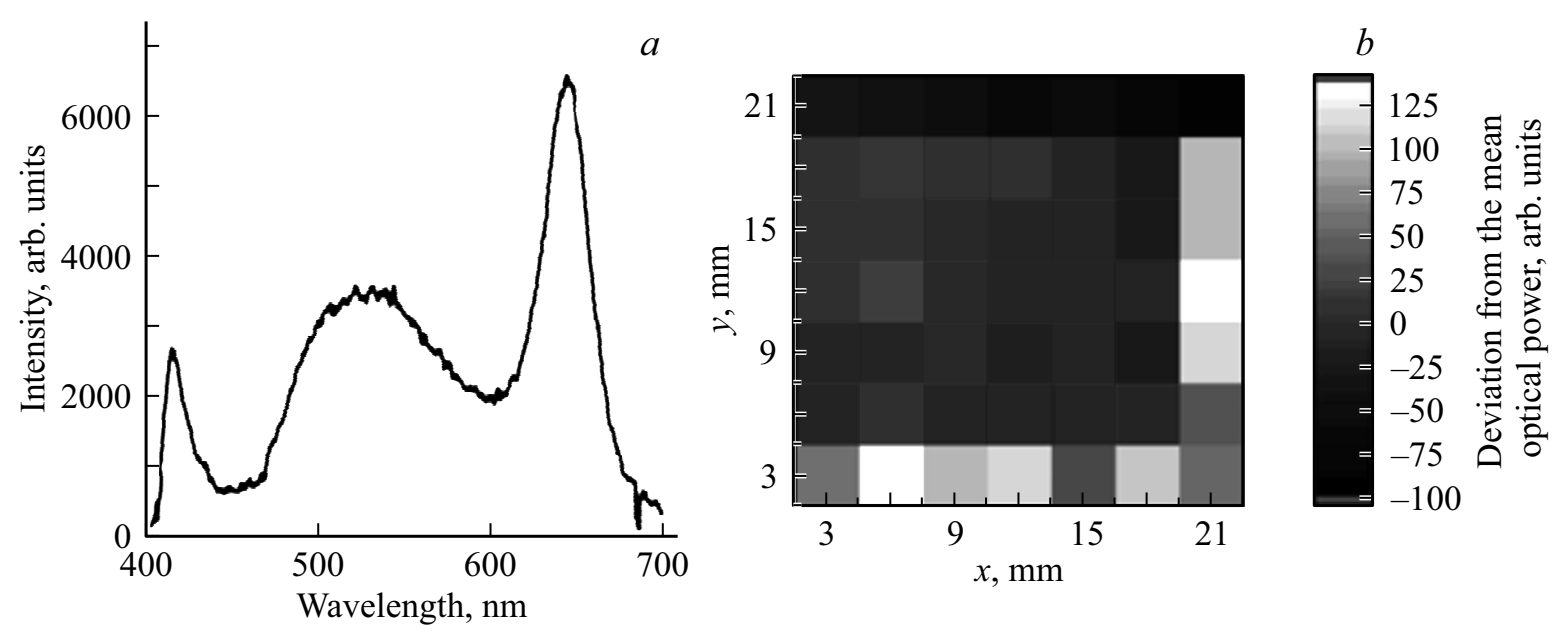

Рис. 2. $a$ - спектр ФЛ структуры ITO/PEDOT:PSS//TPD/TPD + CQD’s CdSe 650/Alq3, $b$ - распределение мощности излучения ФЛ по поверхности образца.

состав структуры приводит к значительной модификации спектра ЭЛ. В длинноволновой области возникает максимум, обусловленный люминесценцией ККТ. Пик, обусловленный люминесценцией Alq3, становится уже. Это объясняется частичным поглощением излучения ККТ. Особенно ярко это выражено в области экситонного пика ККТ на длине волны $600 \mathrm{~nm}$. На вкладке рис. 3 представлена вольт-амперная характеристика структуры ITO/PEDOT:PSS/TPD/TPD + CQD's $\mathrm{CdSe} / \mathrm{Alq3} / \mathrm{Al}$. Вольт-амперная характеристика имеет экспоненциальный вид, что говорит о наличии выпрямляющего контакта в структуре.

На рис. 4 представлены спектры ЭЛ структуры ITO/PEDOT:PSS/TPD/TPD + CQD's CdSe 650/Alq3/Al при различных рабочих напряжениях и фотография работающей структуры. С увеличением напряжения возрастает оптическая мощность излучения вследствие роста числа актов рекомбинации в активных слоях

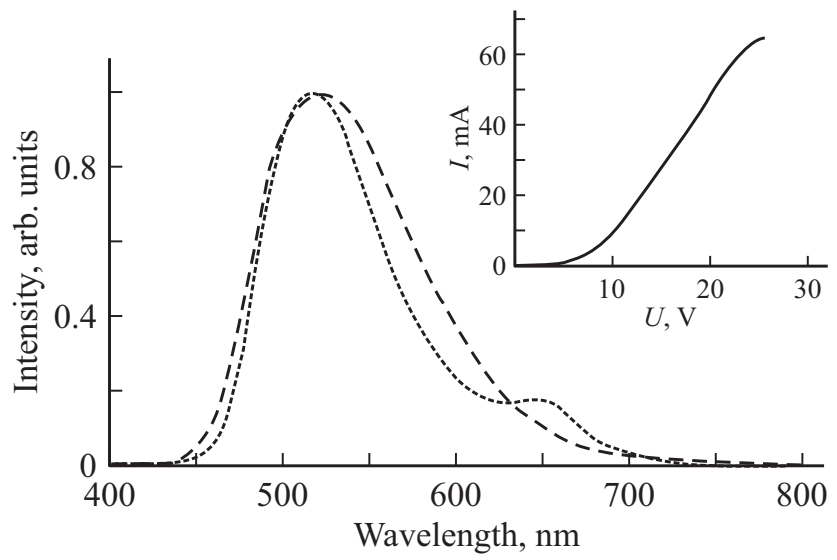

Pис. 3. Спектр ЭЛ структуры ITO/PEDOT:PSS/TPD/Alq3/Al (штриховая кривая), спектр ЭЛ ITO/PEDOT:PSS//TPD/ TPD + CQD's CdSe/Alq3/Al (пунктир). На вкладке - вольтамперная характеристика структуры.

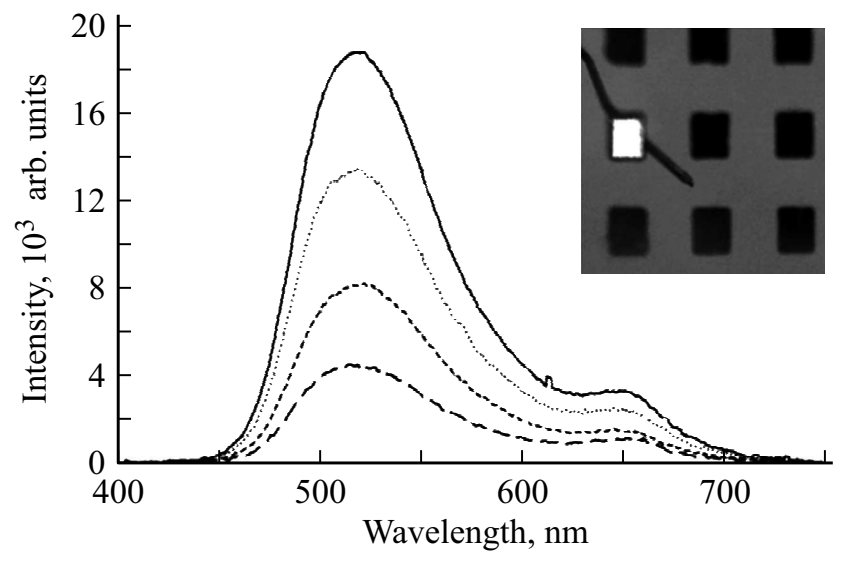

Рис. 4. Спектры ЭЛ структуры ITO/PEDOT: PSS//TPD/ TPD + CQD's CdSe/Alq3/Al при различных рабочих напряжениях: 25 (сплошная кривая), 20 (пунктир), 15 (короткий штрих), $10 \mathrm{~V}$ (длинный штрих). На вкладке - фотография работающей структуры.

структуры. Наблюдается увеличение интенсивности ЭЛ, обусловленной как Alq3, так и ККТ.

\section{Выводы}

Таким образом, в работе были созданы органические светоизлучающие структуры ITO/TPD/Alq3/Al и ITO/PEDOT $:$ PSS/TPD/Alq3/Al, а также структуры ITO/PEDOT: PSS/TPD/TPD + CQD's CdSe/Alq3/Al, coдержащие в своем составе ККТ CdSe/ZnS. При выращивании слоев маломолекулярных соединений была применена нетипичная методика быстрого вакуумного термического осаждения с целью обеспечения высокой однородности нанесения материала и улучшения характеристик структур. Методами ОС была произведена оценка применимости этой методики для создания та- 
ких структур. Измерения показали, что использованная методика позволяет создавать качественные слои TPD и Alq3 за более короткое время, но без ухудшения их физических свойств. Включение в разработанную методику этапа нанесения полимерных слоев PEDOT:PSS методом центрифугирования позволило создать высококачественные структуры, представляющие собой OLED для зеленого диапазона спектра. Также была произведена оценка однородности распределения материала при создании слоев методами термического осаждения и центрифугирования. Сформулированы рекомендации к созданию верхних контактов и других областей светоизлучающих структур с улучшенными характеристиками.

Далее в работе были созданы прототипы органических светоизлучающих структур, содержащих массивы KKT CdSe/ZnS. Достигнута ЭЛ квантовых точек для широкого диапазона подаваемых напряжений. Показано, что введение ККТ в структуру приводит к модификации спектра ЭЛ. В настоящее время ведутся работы по повышению яркости излучения массива ККТ за счет оптимизации процедуры распределения квантовых точек в структуре. Проводятся предварительные работы по введению в состав структуры сформированного многокомпонентного массива ККТ различного состава и размера, обладающего заранее заданным спектром ФЛ $[12,13]$. Использование таких массивов позволит создавать органические структуры, обладающие спектром ЭЛ, близким к спектру излучения Солнца с индексом цветопередачи CRI выше 95, или с любой иной формой спектра излучения.

Работа выполнена в рамках НИР проектной части государственного задания Минобрнауки России в сфере научной деятельности, проект № 16.1750.2017/4.6.

\section{Список литературы}

[1] Murray C.B., Kagan C.R., Bawendi M.G. // Ann. Rev. Mater. Res. 2000. V. 30. P. 545-610.

[2] Colvin V.L., Schlamp M.C., Alivisatos A.P. // Nature. 1994. V. 370. P. 354. doi: 10.1038/370354a0

[3] Coe S., Woo K.W., Bawendi M.G., Bulovic V. // Nature. 2002. V. 420. P. 800. doi: 10.1038/nature01217

[4] Caruge J.M., Halpert J.E., Wood V., Bulovic V., Bawendi M.G. // Nature Photon. 2008. V. 2. P. 247. doi: $10.1038 /$ nphoton. 2008.34

[5] Cho K.S., Lee E.K., Joo W.J., Jang E., Kim T.H., Lee S.J., Kwon S.J., Han J.Y., Kim B.K., Choi B.L., Kim J.M.// Nature Photon. 2009. V. 3. P. 341. doi: 10.1038/nphoton.2009.92

[6] Fengjuan Zhang, Shujie Wang, Lei Wang // Nanoscale. 2016. V. 8. P. 12182-12188. doi: 10.1039/C6NR02922A

[7] Mikhailov I.I., Tarasov S.A., Lamkin I.A., Tadtaev P.O., Kozlovich L.I., Solomonov A.V., Stepanov E.M. // J. Phys. Conf. Ser. 2016. V. 741. P. 012103.

[8] Тарасов С.А, Михайлов И.И., Степанов Е.М., Вылегжсанин Д.В., Гуревич М.О., Козлович Л.И., Корнеева А.В., Тадтаев П.О., Соломонов А.В. // Нано- и микросистемная техника. 2016. Т. 18. № 9. С.558-562.
[9] Haichuan Mu, Hui Shen, Klotzkin D. // Sol.-St. Electron. 2004. V. 48. P. 2085-2088.

[10] Heiskanen J.P., Tolkki A.E., Lemmetyinen H.J., Hormib O.E.O. // J. Mater. Chem. 2011. V. 21. P. 14766-14775.

[11] Vragovic I., Calzado E.M., Díaz García M.A., Himcinschib C., Gisslenc L., Scholzc R. // J. Luminesc. 2008. V. 128. P. 845-847.

[12] Stepanov E.M., Mikhailov I.I., Tarasov S.A., Solomonov A.V. // IEEE. 2016. P. 82-84. doi: 10.1109/EIConRusNW.2016.7448125

[13] Tadtaev P.O., Gurevich M.O., Kozlovich L.I., Mikhailov I.I. // IEEE. 2016. P. 85-87.

doi: 10.1109/EIConRusNW.2016.7448126 